\title{
Sensitivity of Gram-negative bacilli to ampicillin after six years' clinical use
}

\author{
B. SLOCOMBE AND R. SUTHERLAND \\ From Beecham Research Laboratories, Brockham Park, Betchworth, Surrey
}

SYNOPSIS A total of 1,102 clinical isolates of Gram-negative bacilli was obtained from four hospitals during 1967 and these cultures were tested for sensitivity to ampicillin. Approximately $80 \%$ of the strains of Escherichia coli and $90 \%$ of the strains of Proteus mirabilis, the two organisms most frequently isolated, were sensitive to ampicillin. Klebsiella-Enterobacter species and Pseudomonas aeruginosa were generally insensitive. Comparison of these results with data obtained in an earlier study with Gram-negative organisms isolated in 1961 showed that there had been no significant increase in the incidence of resistance of Gram-negative bacilli to ampicillin during the period 1961-67.

The majority of ampicillin-resistant strains of $E$. coli isolated in 1967 transferred ampicillin resistance to a sensitive strain of $E$. coli $\mathrm{K} 12$. Only four ampicillin-resistant strains of $E$. coli isolated in 1961 were available for transferable resistance tests but all four strains transferred ampicillin resistance. Infective or transferable resistance was therefore a feature of ampicillin resistance of certain Gram-negative bacteria before ampicillin became generally available for clinical use.

The relatively recent demonstration of transferable antibiotic resistance among bacteria (Watanabe, 1963) has led to renewed interest in the incidence of antibiotic resistance among Gram-negative bacilli, particularly as these organisms appear to be responsible for an increasing proportion of serious infections within hospitals (Watt and Okubadejo, 1967; Barrett, Casey, and Finland, 1968).

Shortly after the introduction of ampicillin into clinical use in mid-1961 several hundred freshly isolated cultures of Gram-negative bacilli were obtained from three London hospitals, and these organisms were tested for sensitivity to ampicillin, chloramphenicol, and tetracycline (Sutherland and Rolinson, 1964). During 1967 approximately similar numbers of isolates were obtained from the same three London hospitals as in 1961 and these were tested for sensitivity to ampicillin. In addition, a fourth hospital situated just outside the London area supplied approximately 300 cultures which were tested for sensitivity to ampicillin.

The data presented here show the incidence of resistance to ampicillin among Gram-negative bacilli isolated in 1967, and this is compared with the incidence of resistance among organisms isolated in 1961.

Received for publication 13 February 1969.

\section{METHODS}

CULTURES The Gram-negative bacilli used in this study $\overrightarrow{\vec{F}}$ were fresh clinical cultures isolated routinely in the laboratories of the four hospitals concerned in this study and were sent to this laboratory without selection of any kind. The majority of cultures were isolated from urine specimens but a substantial number of organisms from sputum, wound and pus swabs, and faecal specimens were also tested.

CLASSIFICATION The methods used to identify and classify the bacteria were essentially the same as those described in the previous study (Sutherland and Rolinson, 1964) and were based on criteria described by Cowan and Steel (1961).

SENSITIVITY TESTING Minimum inhibitory concentrations were determined by serial dilution of ampicillin in $\mathbb{O}$ nutrient agar. Plates were inoculated by means of an $N$ inoculating device with a drop (approximately $0.003 \mathrm{ml}$ ) $\sigma$ of an overnight broth culture of the test organism and inhibition of growth was determined after overnight incubation at $37^{\circ} \mathrm{C}$.

MEASUREMENT OF INFECTIVE RESISTANCE (TRANSFERABLE RESISTANCE) Ampicillin-resistant isolates of $E$. coli were $\overrightarrow{\mathbb{D}}$ grown overnight in Penassay broth (Oxoid, antibiotic $\frac{O}{\Phi}$ medium no. 3 ), and $0.2 \mathrm{ml}$ volumes of these donor strains $\varrho$ were added to $0.4 \mathrm{ml}$ volumes of an overnight culture of $\bar{\gamma}$ 
the recipient strain $E$. coli $\mathrm{K} 12 / 711 \mathrm{NX}$, a lactose-negative variant resistant to nalidixic acid. The mixed cultures of donor and recipient bacteria were cultured in $9 \mathrm{ml}$ of Penassay broth, and, after overnight incubation at $37^{\circ} \mathrm{C}$, were plated on MacConkey agar containing $25 \mu \mathrm{g} / \mathrm{ml}$ ampicillin and $20 \mu \mathrm{g} / \mathrm{ml}$ nalidixic acid; control plates containing either $25 \mu \mathrm{g} / \mathrm{ml}$ ampicillin or $20 \mu \mathrm{g} / \mathrm{ml}$ nalidixic acid were also inoculated with the mating mixtures. Inoculation of the plates was carried out with a multipoint inoculating device delivering approximately 0.003 $\mathrm{ml}$ of culture. After overnight incubation at $37^{\circ} \mathrm{C}$ the plates were examined for lactose-negative colonies growing in the presence of $25 \mu \mathrm{g} / \mathrm{ml}$ ampicillin and $20 \mu \mathrm{g} / \mathrm{ml}$ nalidixic acid. Lactose-negative colonies were subcultured into Penassay broth and retested for resistance to ampicillin.

\section{RESULTS}

SENSITIVITY TO AMPICILLIN OF ORGANISMS ISOLATED IN 1967 In all, a total of 1,102 strains of Gramnegative bacilli was tested, 233 from hospital 1, 240 from hospital 2, 342 from hospital 3, and 287 from hospital 4. The predominant organisms were $E$. coli $(45 \cdot 1 \%), P$. mirabilis $(22 \cdot 1 \%)$ and Klebsiella-Enterobacter species $(18.3 \%)$. The remainder comprised Ps. aeruginosa $(9.7 \%)$, Proteus species $(2.3 \%)$, and miscellaneous organisms $(2 \cdot 5 \%)$ such as paracolon bacteria, Achromobacter species, and Alkaligenes species (Table I).

Of the total of 497 strains of $E$. coli, 80\% (397 strains) were sensitive to $5 \mu \mathrm{g} / \mathrm{ml}$ ampicillin or less. There was some variation between the four hospitals, ranging from $90.3 \%$ sensitivity at hospital 2 to $66 \%$ sensitivity at hospital 1. At the latter hospital the majority of resistant organisms were received at this laboratory in a single batch of cultures, and it is possible that this group of resistant organisms was associated with cross-infection occurring at the time these cultures were isolated.

The second most common pathogen, $P$. mirabilis ( $22 \%$ of isolates), was also predominantly sensitive,
$93 \%$ (217 strains) being inhibited by $5 \mu \mathrm{g} / \mathrm{ml}$ ampicillin or less. In fact, 208 out of these 217 strains were sensitive to $2.5 \mu \mathrm{g} / \mathrm{ml}$ ampicillin and more than half of the strains isolated were sensitive to 1.25 $\mu \mathrm{g} / \mathrm{ml}$ ampicillin.

In contrast, Klebsiella-Enterobacter species, representing $18 \%$ of the total bacteria, were very much more resistant to ampicillin $(6.4 \%$ sensitive to $5 \mu \mathrm{g} / \mathrm{ml}, 11.9 \%$ sensitive to $12.5 \mu \mathrm{g} / \mathrm{ml}$ ), and strains of Ps. aeruginosa were uniformly insensitive. Proteus species (other than $\boldsymbol{P}$. mirabilis) tended to be resistant to ampicillin, and the majority of the paracolon bacteria tested were also insensitive.

A number of strains of enterococci (Streptococcus faecalis), one of the more common of the pathogens associated with urinary tract infections, were also tested for sensitivity to ampicillin, but these results are not included in the tables as isolates were sent by only two of the four hospitals. Out of 39 strains tested only one strain was resistant to $5 \mu \mathrm{g} / \mathrm{ml}$ ampicillin; the majority (37/39 strains, 95\%) were inhibited by $2.5 \mu \mathrm{g} / \mathrm{ml}$ ampicillin or less.

COMPARISON OF AMPICILLIN SENSITIVITIES OF GRAMNEGATIVE BACILLI ISOLATED IN 1961 AND 1967 The cumulative percentage inhibition by ampicillin of the three most common species, namely, $E$. coli, $\boldsymbol{P}$. mirabilis, and Klebsiella-Enterobacter, isolated at the three London hospitals in 1961 and in 1967, is illustrated in Figure 1. Details of the incidence of ampicillin sensitivity in 1961 and 1967 are presented in Table II.

The proportion of strains of $E$. coli isolated in $1967(42.5 \%)$ was very similar to that of 1961 $(44.5 \%)$ and the same was true for $P$. mirabilis $(25.8 \%$ in 1961 and $23.4 \%$ in 1967$)$. In general, the proportions of strains of these genera sensitive to ampicillin were similar for both studies. For example, $80.9 \%$ of $E$. coli isolated in 1967 were inhibited by $5 \mu \mathrm{g} / \mathrm{ml}$ ampicillin or less; the corresponding figure

TABLE I

AMPICILLIN SENSITIVITY OF 1,102 STRAINS OF GRAM-NEGATIVE BACILLI ISOLATED AT FOUR HOSPITALS IN 1967

\begin{tabular}{|c|c|c|c|c|c|c|c|c|c|c|c|}
\hline \multirow{2}{*}{ Organism } & \multirow{2}{*}{$\begin{array}{l}\text { No. } \\
\text { of } \\
\text { Strains }\end{array}$} & \multirow{2}{*}{$\begin{array}{l}\text { Percen- } \\
\text { tage of } \\
\text { Total }\end{array}$} & \multicolumn{9}{|c|}{ Number of Strains Inhibited by Ampicillin $(\mu \mathrm{g} / \mathrm{ml})$} \\
\hline & & & $>250$ & 250 & 125 & 50 & 25 & $12 \cdot 5$ & $5 \cdot 0$ & $2 \cdot 5$ & $1 \cdot 25$ or less \\
\hline $\begin{array}{l}\text { Escherichia coli } \\
\text { Proteus mirabilis } \\
\text { Klebsiella- }\end{array}$ & $\begin{array}{l}497 \\
244\end{array}$ & $\begin{array}{l}45 \cdot 1 \\
22 \cdot 1\end{array}$ & $\begin{array}{l}49(100 \%)^{3} \\
17(100 \%)\end{array}$ & $\begin{array}{l}3(90.1 \%) \\
4(93.0 \%)\end{array}$ & $\begin{array}{l}8(89.5 \%) \\
1(91.4 \%)\end{array}$ & $\begin{array}{r}4(87.9 \%) \\
-(91.0 \%)\end{array}$ & $\begin{array}{l}5(87 \cdot 1 \%) \\
2(91 \cdot 0 \%)\end{array}$ & $\begin{array}{r}31(86 \cdot 1 \%) \\
3(90 \cdot 2 \%)\end{array}$ & $\begin{array}{r}260(79.9 \%) \\
9(88.9 \%)\end{array}$ & $\begin{array}{r}127(27 \cdot 6 \%) \\
65(85 \cdot 2 \%)\end{array}$ & $\begin{array}{r}10(2.0 \%) \\
143(58.6 \%)\end{array}$ \\
\hline $\begin{array}{l}\text { Enterobacter } \\
\text { Pseudomonas }\end{array}$ & 202 & $18 \cdot 3$ & $88(100 \%)$ & $15(56.4 \%)$ & $29(49 \cdot 0 \%)$ & $28(34 \cdot 7 \%)$ & $18(20 \cdot 1 \%)$ & $11(11.9 \%)$ & $8(6.4 \%)$ & $3(2 \cdot 1 \%)$ & $2(1.0 \%)$ \\
\hline $\begin{array}{l}\text { aeruginosa } \\
{\text { Proteus } \text { species }^{1}}_{\text {Miscellaneous }^{2}}\end{array}$ & $\begin{array}{r}107 \\
25 \\
27\end{array}$ & $\begin{array}{l}9 \cdot 7 \\
2 \cdot 3 \\
2 \cdot 5\end{array}$ & $\begin{array}{c}103(100 \%) \\
10(100 \%) \\
9(100 \%)\end{array}$ & $\begin{array}{l}2(3.7 \%) \\
5(60.0 \%) \\
1(66.7 \%)\end{array}$ & $\begin{array}{r}2(1.9 \%) \\
3(40.0 \%) \\
-(63.0 \%)\end{array}$ & $\begin{array}{l}-5(28.0 \%) \\
1(63.0 \%)\end{array}$ & $\begin{array}{r}-1 \quad(8.0 \%) \\
-(59.3 \%)\end{array}$ & $\begin{array}{c}-1(4.0 \%) \\
4(59 \cdot 3 \%)\end{array}$ & $10 \overline{(25.5 \%)}$ & $\bar{L}^{-}$ & - \\
\hline Total & 1,102 & & & & & & & & & & \\
\hline \multicolumn{12}{|c|}{$\begin{array}{l}P . \text { morganii, } P \text {. rettgeri, } P \text {. vulgaris } \\
\text { Mainly Paracolon, Achromobacter, and Alkaligenes } \\
\% \text { cumulative inhibition shown in brackets) }\end{array}$} \\
\hline
\end{tabular}


Escherichia coli

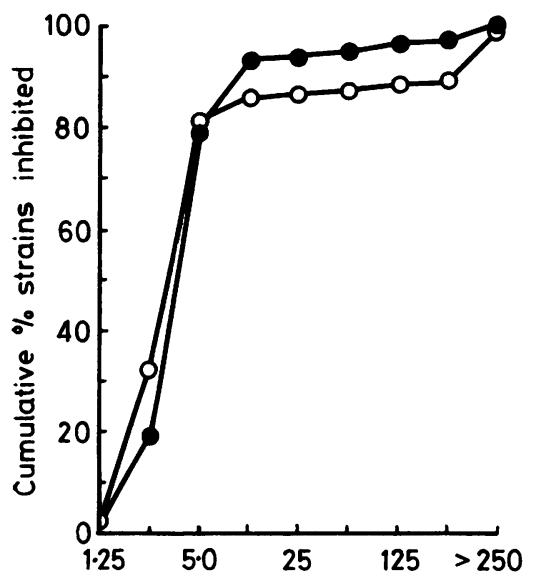

Proteus mirabilis

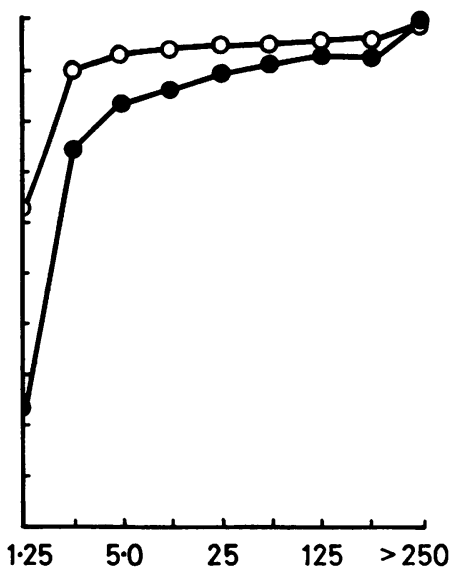

Ampicillin concentration $(\mu \mathrm{g} / \mathrm{ml})$

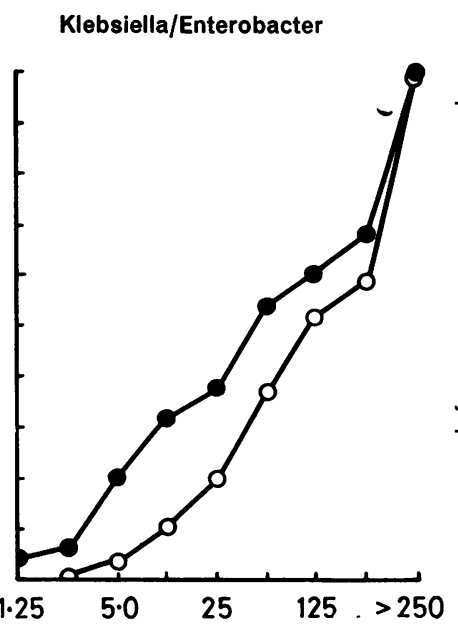

.

FIG. 1. Susceptibility to ampicillin of Gram-negative bacilli isolated in 1961 (O) and 1967 (O).

Escherichia coli 1961, 269 strains; 1967, 346 strains; Proteus mirabilis, 1961, 156 strains; 1967, 191 strains; KlebsiellaEnterobacter 1961, 80 strains; 1967, 156 strains.

\section{TABLE II}

SUSCEPTIBILITY TO $5 \mu \mathrm{G} / \mathrm{ML}$ AMPICILLIN OF GRAMNEGATIVE BACILLI ISOLATED IN 1967 AND IN 19611

\begin{tabular}{|c|c|c|c|c|}
\hline \multirow[b]{2}{*}{ Organism } & \multicolumn{2}{|l|}{1967} & \multicolumn{2}{|l|}{1961} \\
\hline & $\begin{array}{l}\text { No. } \\
\text { Strains } \\
\text { Tested }\end{array}$ & $\begin{array}{l}\text { No. } \\
\text { Inhibited by } \\
5 \mu g / m l \\
\text { Ampicillin }\end{array}$ & $\begin{array}{l}\text { No. } \\
\text { Strains } \\
\text { Tested }\end{array}$ & $\begin{array}{l}\text { No. } \\
\text { Inhibited by } \\
5 \mu \mathrm{g} / \mathrm{ml} \\
\text { Ampicillin }\end{array}$ \\
\hline
\end{tabular}

\section{Escherichia}

coli

Proteus

mirabilis $191(23.4 \%) \quad 178(93.2 \%) \quad 156(25.8 \%) \quad 130(83.3 \%)$

Klebsiella-

Enterobacter $156(19.1 \%) \quad 6(3.8 \%) \quad 80(13.2 \%) \quad 16(20.0 \%)$

Pseudomonas

$\begin{array}{llllllll}\text { aeruginosa } & 92(11.3 \%) & 0 & 0 & 47 & (7.8 \%) & 1 & (2.1 \%)\end{array}$

Proteus

$\begin{array}{lllllllll}\text { species } & 19 & (2.3 \%) & 0 & 0 & 13 & (2 \cdot 1 \%) & 1 & (7 \cdot 7 \%)\end{array}$

Miscellaneous $11(1.3 \%) \quad 3(27 \cdot 3 \%) \quad 40 \quad(6.6 \%) \quad 19(47.5 \%)$

Total

815

605

'Organisms isolated at the same three London hospitals

for $E$. coli isolated in 1961 was $78.8 \%$ (Table II). It is true that $11 \%$ of the strains of $E$. coli isolated in 1967 were not inhibited by $250 \mu \mathrm{g} / \mathrm{ml}$ ampicillin, compared with a figure of $3 \%$ for 1961 , but in part this may be due to cross-infection at one of the hospitals in 1967 as described previously. With $P$. mirabilis the proportion of ampicillin-sensitive strains isolated in $1967(93.2 \%)$ was similar to that of $1961(83.3 \%)$. If anything, this genus was more sensitive in 1967 than in 1961.

Strains of Klebsiella-Enterobacter were apparently more common in 1967 than in $1961(19.1 \%$ compared with $13.2 \%$ ); in part this may have been due to stricter classification in the later study, $i e$, some of the organisms classified in 1967 as KlebsiellaEnterobacter species were probably classified as $\stackrel{\varnothing}{\varnothing}$ miscellaneous bacteria in 1961. In both years, this $\vec{P}$ group of organisms was largely resistant to ampi- $\cong$ cillin, possibly more so in 1967 than in 1961. The numbers of Ps. aeruginosa were slightly higher in $1967(11.3 \%)$ than in $1961(7.8 \%)$, and in both years these organisms were uniformly resistant to ampi-? cillin. The incidence of Proteus species (P. morganii, $P$. rettgeri, and $P$. vulgaris) remained the same (approximately $2 \%$ ), and fewer cultures were classified as miscellaneous bacteria in $1967(1.3 \%)$ than in $1961(6 \cdot 6 \%)$ for the reason given above.

TETRACYCLINE RESISTANCE AT HOSPITAL 3 IN 1961 을 AND 1967 Most of the cultures isolated in 1967 at $\sim$ hospital 3 were also tested for sensitivity to tetracycline. Figure 2 shows the percentage cumulative inhibition by tetracycline of E. coli, $P$. mirabilis, $\stackrel{\omega}{ }$ and Klebsiella-Enterobacter isolated in 1961 and 1967. As was the case for ampicillin there was noc great difference in the incidence of resistance to $\Phi$ tetracycline of cultures isolated in 1961 and in 1967. Thus $71 \%$ of the strains of $E$. coli isolated in 1967 were inhibited by $5 \mu \mathrm{g} / \mathrm{ml}$ tetracycline; the corres- $\frac{0}{0}$ ponding figure for 1961 was $72 \%$. Similarly, $71 \%$ of $\frac{?}{\odot}$ the Klebsiella-Enterobacter isolated in 1967 were 0 sensitive to tetracycline compared with $50 \%$ of $16 \%$ 


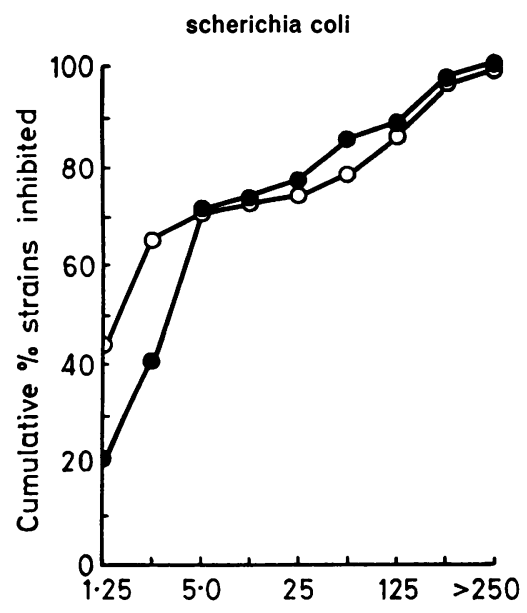

Proteus mirabilis

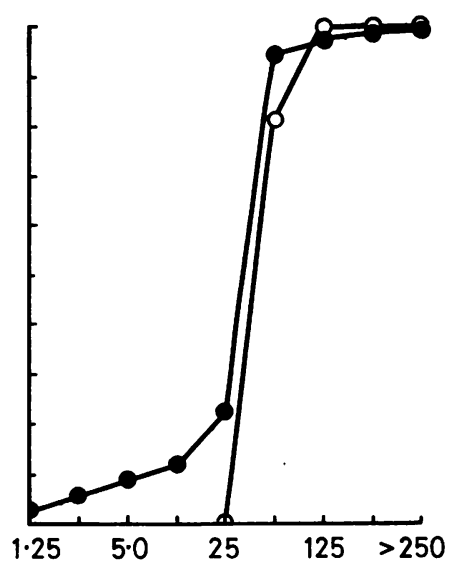

Tetracycline concentration $(\mu \mathrm{g} / \mathrm{ml})$
Klebsiella/Enterobacter

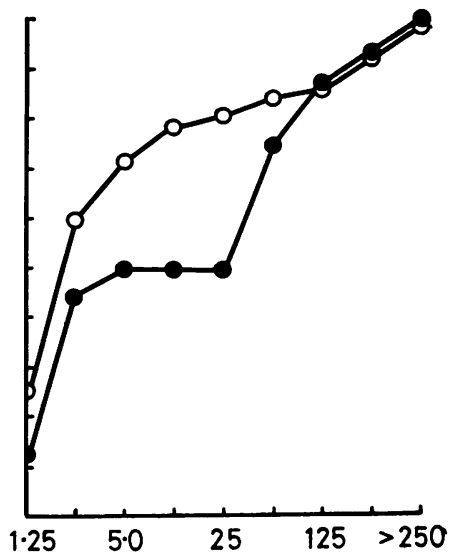

FIG. 2. Susceptibility to tetracycline of Gram-negative bacilli isolated in 1961 (O) and 1967 (O).

Escherichia coli 1961, 88 strains; 1967, 137 strains; Proteus mirabilis 1961, 36 strains; 1967, 58 strains; KlebsiellaEnterobacter 1961, 16 strains; 1967, 52 strains.

strains isolated in 1961. The majority of strains of $P$. mirabilis and Ps. aeruginosa were insensitive to tetracycline in 1967 as was the case in 1961.

INFECTIVE RESISTANCE AMONG AMPICILLIN-RESISTANT STRAINS OF E. coli A total of 33 strains (out of 49 strains) isolated in 1967 resistant to $250 \mu \mathrm{g} / \mathrm{ml}$ ampicillin were tested for ability to transfer ampicillin resistance to the ampicillin-sensitive organism E. coli K12/711 NX. Of these strains, $23(70 \%)$ transferred ampicillin resistance to the recipient strain.

Only seven of the strains of $E$. coli isolated in 1961 and found to be resistant to ampicillin were available for tests of transferable resistance. Three of these cultures had lost their resistance and were sensitive to ampicillin. The remaining four cultures were insensitive to ampicillin and transferred their resistance to $E$. coli $\mathrm{K} 12 / 711$.

\section{DISCUSSION}

The results presented here show that there has been no marked increase in the incidence of ampicillin resistance among Gram-negative bacilli in the hospitals in question since the introduction of this antibiotic into clinical use in 1961. In this study of bacteria isolated in 1967, and in the earlier study of organisms isolated in 1961, the majority of strains of the two most commonly isolated pathogens, namely, $E$. coli and $P$. mirabilis, were sensitive to ampicillin, while Klebsiella-Enterobacter species and $P$ s. aeruginosa were generally insensitive. A recent study in the United States involving over 4,000 isolates of Gram-negative bacteria recorded a similar distribution of sensitivity to ampicillin (Turck, 1967).

It is also of interest that the limited study of the incidence of tetracycline resistance among bacteria isolated at one hospital in 1961 and in 1967 indicated that there had been no significant change in resistance to tetracycline between 1961 and 1967. Recent studies in the USA (Bulger, Roberts, and Sherris, 1967; Petersdorf and Turck, 1966) have also reported no appreciable increase in the resistance of Gramnegative bacilli to a variety of antibiotics between 1959 and 1965. These studies did not include ampicillin, but the results reported here indicate that ampicillin appears to be no different from other antibiotics in this respect.

These findings may appear surprising in the light of the relatively recent awareness of the ability of Gram-negative bacteria to transfer antibiotic resistance to other bacteria, and subsequent speculation regarding the possibility of a rapid increase in the incidence of antibiotic resistance among Gramnegative bacteria. Our results confirm that the majority of resistant strains of $E$. coli isolated in 1967 were able to transfer ampicillin resistance in vitro to a suitable ampicillin-sensitive recipient strain. However, we were also able to demonstrate transfer of ampicillin resistance from four strains of $E$. coli isolated in 1961 soon after ampicillin became available for clinical use. It is a possibility therefore that the ampicillin resistance of certain Gramnegative bacilli has always been largely associated with transferable resistance, and that it is not 
necessarily a relatively new phenomenon. Unfortunately, only a limited number of bacteria isolated in the early 1960s were available to us, so we can draw no conclusions as to whether there has been any change in the incidence of strains of $E$. coli carrying $\mathrm{R}$ factors.

As $\mathbf{R}$ factors have evidently been present in Gramnegative bacilli over a relatively long period of time, and as ampicillin resistance can be readily transferred in vitro, it may be asked why there has not been an obvious increase in the incidence of ampicillin resistance among Gram-negative bacteria. There are various possibilities, including factors in vivo which affect the efficiency of transfer, incompatability between bacteria, and spontaneous loss of $\mathrm{R}$ factors. Whatever the reason, it is encouraging that the results reported here show no evidence of increased resistance to ampicillin among Gram-negative bacilli after six years' clinical usage.
We are grateful to Dr J. Harding of the West Middlesex Hospital, Dr J. P. Mackey of Redhill General Hospital, Dr M. Ridley of St Thomas' Hospital, and Dr R. E. M.O Thompson, Middlesex Hospital, for kindly providing the $\frac{C}{0}$ cultures described here.

It is a pleasure to thank Mrs Eleanor Fairclough and $\vec{\nabla}$

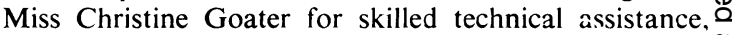
and Dr G. N. Rolinson for much helpful advice and criticism.

\section{REFERENCES}

Barrett, F. F., Casey, J. I., and Finland, M. (1968). New Engl. J. Med.응 278, 5 .

Bulger, R. J., Roberts, C. E., and Sherris, J. C. (1967). Antimicrob. N Agents Chemother., 6, 42.

Cowan, S. T., and Steel, K. J. (1961). J. Hyg. (Lond.), 59, 357.

Petersdorf, R. G., and Turck, M. (1966). Ann. N. Y. Acad. Sci., 132, 834.

Sutherland, R., and Rolinson, G. N. (1964). J. clin. Patí., 17, 461.

Turck, M. (1967). Antimicrob. Agents Chemother., 6, 265.

Watanabe, T. (1963). Bact. Rev., $27,87$.

Watt, P. J., and Okubadejo, O. A. (1967). Brit. med. J., 1, 210. 